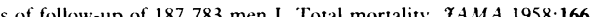
$1159-72$

27 Doll R, Peto R. Mortality in relation to smoking: 20 years' observations on male British doctors. Br.Med J 1976;ii:1525-36.

28 Stamler R. Influence of treatment of "mild" hypertension on coronary heart disease. Acta Med Scand 1958;701(suppl):89-99.

29 Steinberg D. Lipoproteins and atherosclerosis. A look back and a look ahead. George Lyman Duff memorial lecture. Arteriosclerosis 1983;3:283-301.

30 Holme I, Solberg LA, Weissfeld L, et al. Coronary risk factors and their pathway of action through coronary raised lesions, coronary stenoses and coronary death. Am J Cardiol 1985;55:40-7.

31 Hollander $W$. Role of hypertension in atherosclerosis and cardiovascular disease. Am F Cardiol 1976;38:786-800.
32 US Department of Health and Human Services. The health consequences of smoking. Cardiovascular disease: a report of the surgeon general. Rockville, Maryland: US Department of Health and Human Services, 1983. (DHHS publication No (PHS) 84-50204.)

33 Cox D. Regression models and life tables (with discussion). Fournal of the Royal Statistical Society 1972;34B:187-220.

34 Rose G. Strategy of prevention: lessons from cardiovascular disease. $\mathrm{Br}$ Med $\mathcal{F}$ $1981 ; 282: 1847-51$.

35 National Cholesterol Education Program Panel. Report on detection, evaluation, and treatment of high blood cholesterol in adults. Arch Intern Med 1988;148:36-69.

(Accepted 10 April 1989)
Institute of Community Medicine, University of Troms $\varnothing$, Box 417, N-9001 Tromsø, Norway

Vidje Hansen, MD, senior consultant

Bjarne K Jacobsen, PHD, senior lecturer

Correspondence and requests for reprints to: Dr Hansen.

\title{
Mental distress and social conditions and lifestyle in northern Norway
}

\author{
Vidje Hansen, Bjarne K Jacobsen
}

\begin{abstract}
In a cross sectional survey of risk factors for coronary heart disease three questions about mental distress were included in a questionnaire completed by 13704 people, $64 \%$ of the total population aged $20-54$ in one municipality. Overall, $860(12 \cdot 5 \%)$ of the men and $1141(16.8 \%)$ of the women reported having at least one symptom of mental distress. There were no distinct differences between the age groups. Single people, separated and divorced people, and those who reported that the financial situation of the family during their childhood was difficult reported more mental problems. Heavy smoking, frequent alcohol consumption, and, in men, little or no physical activity in leisure time were also associated with a high prevalence of mental distress. By multiple regression analyses, marital state, financial situation of family during childhood, and current lifestyle were found to be highly significantly associated with mental distress.
\end{abstract}

Including a few questions on mental distress in health surveys provides a way to establish relations between such symptoms and social conditions and lifestyle in large numbers of subjects.

\section{Introduction}

The prominence of mental distress is well documented. In Western societies the prevalence among adults is generally accepted to lie at $10-20 \%$, taking all different conditions together. ${ }^{1-6}$ In current psychiatric epidemiology much emphasis is put on detailed classification of symptom-complexes within systems such as the Diagnostic and Statistical Manual for Mental Disorders third edition and the International Classification of Diseases ninth edition ${ }^{2-6}$ to make comparison between studies possible.

Our aim was not to report prevalence of different psychiatric conditions but rather to describe associations between social and lifestyle variables and prevalence of mental distress. Thus we chose an approach different to that commonly used. By posing three questions about mental symptoms in a general survey of risk factors for coronary heart disease, we sacrificed detail on diagnosis. We were thereby able to obtain information about symptoms of mental distress in more than 13000 adults and to describe relations between the prevalence of these symptoms and other variables that were part of the survey. The results indicate that this approach is a useful supplement to the more common focus on accurate diagnosis.

\section{Subjects and methods}

In 1979-80 all men and women aged 20-54 and 20-49, respectively, living in Troms $\varnothing$, Norway, were invited to participate in a survey of risk factors for coronary heart disease. Details concerning the methods of the study have been given elsewhere.? The invited population comprised 21329 people, and $16621(78 \%)$ attended the screening. They filled in a self administered questionnaire on such topics as smoking habit, physical activity in leisure time, and ethnic origin, which was part of the letter of invitation. At the screening height, blood pressure, and weight were measured, and a blood sample was taken. A second questionnaire to be filled in at home was distributed and 14667 subjects completed it. In this questionnaire the respondents were asked about topics such as length of education, financial state of family during their childhood, and alcohol habits, and there were three questions about symptoms of mental distress.

The questions about symptoms of mental distress were selected from the general health questionnaire which was designed to be used for screening for nonpsychotic psychiatric illness in general populations. ${ }^{8}$ In a study of patients referred by general practitioners in Troms $\emptyset$ for ambulatory psychiatric treatment a version with 21 questions was used. A multiple regression analysis of the answers from 148 patients showed that six questions explained $86 \%$ of the variance in the total score on the questionnaire. Also, in another study of 112 adults admitted to a surgical ward because of accidents the same six questions explained $88 \%$ of the variance in the total score (U Malt, personal communication). The three questions included in the present questionnaire were selected from these six questions on the basis of what seemed most likely to be accepted and understood by the general population. The selected questions were: "During the last two weeks have you had difficulty with sleeping; been feeling unhappy and depressed; felt you couldn't overcome your difficulties?"

The question about sleep was different from that in the general health questionnaire, which is "Have you had difficulty in getting off to sleep?" This modification was made to make the question cover a broader range of sleeping problems. There were four possible answers: not at all, not more than usual, rather more than usual, and much more than usual. In assigning scores to the categories we used the method advocated by Goldberg in which the alternatives "not at all" and "not more than usual" were given the value 0 and the two others were both given the value $1 .{ }^{8} \mathrm{~A}$ total of 6903 men and 6801 women answered all three questions about symptoms of mental distress, and the present analyses were restricted to these subjects.

The associations between age and sex and mental distress were tested by the $\chi^{2}$ test. The relations between mental distress and the different independent variables considered 'were tested by analysis of 
variance; for continuous variables (such as smoking and alcohol consumption) we also tested for linear trend. The impact of an independent variable adjusted for the effect of other variables was tested by multiple regression analysis. The survey was done over 10 months, from May to March, and the various geographical parts of the municipality were surveyed in different months. In our preliminary studies a distinct seasonal variation in the prevalence of mental distress was disclosed, with the highest prevalence in winter. Thus, in the multiple regression analyses the variable "time of year of investigation" was included dividing the survey period in two: May to October and November to March. All analyses were performed with the statistical package for the social sciences (SPSSX). ${ }^{10}$

\section{Results}

Table I gives the prevalence of reported mental distress by age and sex. A total of $860(12 \cdot 5 \%)$ men and $1141(16.8 \%)$ women reported having one or more of the symptoms of mental distress. The difference between the sexes was significant $(p<0.001)$. There was no clear linear association between age and prevalence of the three symptoms, though there was a tendency for more symptoms to be reported by the younger age groups, particularly for those subjects reporting one or more symptoms.

Table II shows the relation between social conditions and lifestyle and the prevalence of reporting at least one of the three different symptoms. Adjustment for age changed the results only negligibly (data not shown). Because of missing information the number of men and women included in the analyses differed among variables. We used "one or more symptoms" as the dependent variable for two reasons. There were high correlations between the three variables that conveyed information about mental distress $(r=0.37$ to $0 \cdot 70$, $\mathrm{p}<0.001$ ), but, most importantly, the relation between the independent variables and the prevalence of the three different symptoms of mental distress were similar.

Married subjects reported fewer symptoms than single ones (overall prevalence $13 \% v 17 \%$ ). Divorced and separated men and women reported particularly high levels of symptoms (overall prevalence $22 \%$ ). The 19 widowers reported fairly few problems, but this was most probably a chance finding $(95 \%$ confidence interval for the proportion of the widowers who reported mental distress $1 \%$ to $33 \%$ ). Years of education had a weak positive association with mental distress in men $(p \leqslant 0.001)$. There was no association between ethnic origin (Norwegian, Lapp, or Finnish) and the frequency of reporting symptoms of mental distress. Women who stated housekeeping as their main occupation reported symptoms less often than employed women. The financial situation in the family during childhood had a considerable effect on the tendency to report mental distress.

Men and women with a lifestyle generally considered unhealthy (low physical activity, heavy smoking, and frequent use of alcohol) reported symptoms of mental distress fairly often, though the differences regarding physical activity did not reach significance in women. Particularly high prevalence was found among the few

TABLE II-Prevalence of symptoms of mental distress according to social and lifestyle variables in Tromso, 1979-80. Figures are numbers (percentages)

\begin{tabular}{|c|c|c|}
\hline & $\begin{array}{c}\text { Men } \\
(n=6903)\end{array}$ & $\begin{array}{c}\text { Women } \\
(n=6801)\end{array}$ \\
\hline \multicolumn{3}{|c|}{ Marital state } \\
\hline $\begin{array}{l}\text { Married } \\
\text { Single } \\
\text { Divorced } \\
\text { Separated } \\
\text { Widow or widower }\end{array}$ & $\begin{array}{l}4497(11)^{\star \star \star}+ \\
2006(15) \\
223(16) \\
106(19) \\
19(11)\end{array}$ & $\begin{array}{l}4609(15) \star \star \star \dagger \\
1705(20) \\
252(27) \\
123(27) \\
63(22)\end{array}$ \\
\hline \multicolumn{3}{|c|}{ Years of education } \\
\hline $\begin{array}{l}<8 \\
8-12 \\
>12\end{array}$ & $\begin{array}{l}1228(10)^{\star \star \star} \ddagger \\
3474(12) \\
2110(14)\end{array}$ & $\begin{array}{l}964(16) \text { NS } \\
4022(17) \\
1742(18)\end{array}$ \\
\hline \multicolumn{3}{|c|}{ Ethnic origin } \\
\hline $\begin{array}{l}\text { Norwegian } \\
\text { Finnish } \\
\text { Lapp } \\
\text { Finnish or Lapp }\end{array}$ & $\begin{array}{l}5552(12) \mathrm{NS} \dagger \\
264(11) \\
162(15) \\
42(14)\end{array}$ & $\begin{array}{l}5353(17) \mathrm{NS} \dagger \\
309(19) \\
139(21) \\
49(14)\end{array}$ \\
\hline \multicolumn{3}{|c|}{ Housekeeper as main occupation } \\
\hline $\begin{array}{l}\text { Yes } \\
\text { No }\end{array}$ & & $\begin{array}{l}2784(15)^{\star \star \dagger} \\
4012(18)\end{array}$ \\
\hline \multicolumn{3}{|c|}{ Financial state of family in childhood } \\
\hline $\begin{array}{l}\text { Very difficult } \\
\text { Difficult } \\
\text { Good } \\
\text { Very good }\end{array}$ & $\begin{array}{l}274(22)^{\star \star \star} \ddagger \\
2266(15) \\
4010(11) \\
284(11)\end{array}$ & $\begin{array}{l}223(24)^{\star \star \star} \ddagger \\
1729(20) \\
4389(15) \\
404(17)\end{array}$ \\
\hline \multicolumn{3}{|c|}{ Physical activity in leisure time } \\
\hline $\begin{array}{l}\text { Sedentary activity } \\
\text { Easy activity } \\
\text { Keep fit activity } \\
\text { Heavy training }\end{array}$ & $\begin{array}{l}1390(17)^{\star \star \star} \ddagger \\
3161(12) \\
1970(11) \\
372(11)\end{array}$ & $\begin{array}{l}1450(19) \mathrm{NS} \ddagger \\
4489(16) \\
775(15) \\
78(15)\end{array}$ \\
\hline \multicolumn{3}{|c|}{ Cigarette smoking } \\
\hline $\begin{array}{l}\text { No of cigarettes/day: } \\
0 \\
1-10 \\
11-20 \\
>20\end{array}$ & $\begin{array}{l}3638(11)^{\star \star \star} \ddagger \\
1264(10) \\
1694(15) \\
307(21)\end{array}$ & $\begin{array}{l}3642(15)^{\star \star \star} \ddagger \\
1962(15) \\
1114(24) \\
80(36)\end{array}$ \\
\hline \multicolumn{3}{|c|}{ Intoxicated by alcohol } \\
\hline $\begin{array}{l}\text { Never or not during last year } \\
\text { Few times/year } \\
1-2 \text { Times/month } \\
>2 \text { Times/month }\end{array}$ & $\begin{array}{l}1457(10)^{\star \star \star} \ddagger \\
3382(11) \\
1593(14) \\
408(23)\end{array}$ & $\begin{array}{l}3302(14)^{\star \star \star} \ddagger \\
2812(19) \\
494(25) \\
78(41)\end{array}$ \\
\hline \multicolumn{3}{|c|}{ Use of alcohol (times/month) } \\
\hline $\begin{array}{l}<4 \\
4-7 \\
8-11 \\
12-15 \\
>15\end{array}$ & $\begin{array}{l}3315(11)^{\star \star \star} \ddagger \\
1703(12) \\
794(14) \\
536(17) \\
373(21)\end{array}$ & $\begin{array}{l}4682(15)^{\star \star \star} \ddagger \\
1276(20) \\
351(21) \\
177(25) \\
71(30)\end{array}$ \\
\hline \multicolumn{3}{|c|}{ Body mass index $\left(\mathrm{kg} / \mathrm{m}^{2}\right)$} \\
\hline $\begin{array}{l}<20 \text { (Underweight) } \\
20-24 \cdot 9 \text { (Normal) } \\
25-29 \cdot 9 \text { (Overweight }) \\
\geqslant 30 \text { (Obese) }\end{array}$ & $\begin{array}{l}264(17) \mathrm{NS} \ddagger \\
4084(12) \\
2219(12) \\
230(13)\end{array}$ & $\begin{array}{l}1205(19) \text { NS } \ddagger \\
4270(17) \\
957(16) \\
194(15)\end{array}$ \\
\hline
\end{tabular}

Fluctuations in numbers reflect missing data.

$\star \star p \leqslant 0 \cdot 01 .{ }^{\star \star \star} p \leqslant 0 \cdot 001$.

$t p$ Value for difference between groups (analysis of variance). $\neq \mathrm{p}$ Value for linear trend.

TABLE I - Prevalence of self reported insomnia, depression, and problems with coping by age and sex in Tromso, 1979-80. Figures are numbers (percentages)

\begin{tabular}{|c|c|c|c|c|c|c|c|c|c|c|}
\hline \multirow{3}{*}{$\begin{array}{l}\text { Age } \\
\text { group }\end{array}$} & \multirow[b]{3}{*}{ Men } & \multirow[b]{3}{*}{ Women } & \multicolumn{8}{|c|}{ Self reported symptoms of mental distress } \\
\hline & & & \multicolumn{2}{|c|}{ Insomnia } & \multicolumn{2}{|c|}{ Depression } & \multicolumn{2}{|c|}{ Coping } & \multicolumn{2}{|c|}{ One or more symptoms } \\
\hline & & & Men & Women & Men & Women & Men & Women & Men & Women \\
\hline $20-$ & 801 & 1176 & $37(4 \cdot 6)$ & $103(8 \cdot 8)$ & $78(9 \cdot 7)$ & $160(13 \cdot 6)$ & $46(5 \cdot 7)$ & $98(8 \cdot 3)$ & $110(13 \cdot 7)$ & $238(20 \cdot 2)$ \\
\hline $25-$ & 1230 & 1488 & $76(6 \cdot 2)$ & $120(8 \cdot 1)$ & $121(9 \cdot 8)$ & $190(12 \cdot 8)$ & $90(7 \cdot 3)$ & $113(7 \cdot 6)$ & $173(14 \cdot 1)$ & $256(17 \cdot 2)$ \\
\hline $30-$ & 1433 & 1516 & $76(5 \cdot 3)$ & $107(7 \cdot 1)$ & $126(8 \cdot 8)$ & $159(10 \cdot 5)$ & $81(5 \cdot 7)$ & $101(6 \cdot 7)$ & $187(13.0)$ & $232(15 \cdot 3)$ \\
\hline $35-$ & 1157 & 1137 & $44(3.8)$ & $96(8 \cdot 4)$ & $98(8.5)$ & $113(9.9)$ & $57(4.9)$ & $64(5 \cdot 6)$ & $129(11 \cdot 1)$ & $181(15.9)$ \\
\hline $40-$ & 834 & 802 & $43(5 \cdot 2)$ & $63(7 \cdot 9)$ & $65(7 \cdot 8)$ & $84(10 \cdot 5)$ & $47(5 \cdot 6)$ & $55(6.9)$ & $95(11 \cdot 4)$ & $126(15 \cdot 7)$ \\
\hline 45- & 738 & 682 & $51(6.9)$ & $50(7 \cdot 3)$ & $67(9 \cdot 1)$ & $83(12 \cdot 2)$ & $47(6 \cdot 4)$ & $53(7 \cdot 8)$ & $95(12.9)$ & $108(15 \cdot 8)$ \\
\hline $50-54$ & 710 & & $38(5 \cdot 4)$ & & $40(5 \cdot 6)$ & & $35(4 \cdot 9)$ & & $71(10 \cdot 0)$ & \\
\hline Total & 6903 & 6801 & $365(5 \cdot 3)$ & $539(7 \cdot 9)$ & $595(8 \cdot 6)$ & $789(11 \cdot 6)$ & $403(5 \cdot 8)$ & $484(7 \cdot 1)$ & $860(12 \cdot 5)$ & $1141(16 \cdot 8)$ \\
\hline
\end{tabular}


women who reported frequent intoxication $(41 \%)$ and frequent use of alcohol (30\%). Body mass index $\left(\right.$ weight/height ${ }^{2}$ ) showed no relation with mental distress.

Overall, 279 (2\% of the 13704$)$ people reported having all three symptoms of mental distress. In separate analyses we examined the relation between the independent variables given in table II and the frequency of reporting all three symptoms. These analyses gave the same general picture as seen in table II. Some of the independent variables were intercorrelated. To determine the variables that contributed independently multiple regression analyses were performed. Ethnic origin and body mass index showed no significant associations with mental distress and were not included in these analyses. Table III shows that marital state $(\mathrm{p}<0.01$ for men and $\mathrm{p}<0.001$ for women), financial situation in family during childhood $(\mathrm{p}<0.001)$, and current lifestyle were independently and highly significantly associated with mental distress. Age and being a full time housewife were not independently associated with mental distress.

TABLE III $-t$ Values for independent variables included in multiple regression analysis describing associations between social and lifestyle variables and one or more symptoms of mental distress $\dagger$ in Tromso, 1979-80

\begin{tabular}{lcc}
\hline \multicolumn{1}{c}{ Variable } & Men & Women \\
\hline Age & $-1 \cdot 87$ & $-0 \cdot 44$ \\
Married & $-2 \cdot 94^{\star \star}$ & $-4 \cdot 04^{\star \star \star}$ \\
Years of education & $2 \cdot 32^{\star}$ & $0 \cdot 39$ \\
Being a full time housewife & & $-0 \cdot 41$ \\
Financial state of family in childhood & $-7 \cdot 18^{\star \star \star}$ & $-5 \cdot 95^{\star \star \star}$ \\
Physical activity in leisure time & $-3 \cdot 29^{\star \star \star}$ & $-1 \cdot 44$ \\
No of cigarettes/day & $2 \cdot 82^{\star \star}$ & $4 \cdot 40^{\star \star \star}$ \\
Frequency of use of alcohol & $3 \cdot 19^{\star \star}$ & $3 \cdot 26^{\star \star \star}$ \\
Frequency of intoxication by alcohol & $1 \cdot 83$ & $3 \cdot 73^{\star \star \star}$
\end{tabular}

Adjusted $\mathrm{R}^{2}$ for $\mathrm{men}=0.025$ and for women $=0.033$.

${ }^{\star} \mathrm{p}<0 \cdot 05 ;{ }^{\star \star} \mathrm{p}<0 \cdot 01 ;{ }^{\star \star \star} \mathrm{p}<0 \cdot 001$.

†Also adjusted for seasonal variation in prevalence of symptoms.

\section{Discussion}

Non-response bias may be important in a study like this. A total of $16621(78 \%)$ of those invited to the screening attended it. Non-attenders tended to be young, single men. Of the 16621 subjects who attended the screening, 1954 did not return the questionnaire. Non-responders to the questionnaire differed little from the responders regarding age, body mass index, blood lipids, and blood pressure, but the responders tended to be married and non-smokers. ${ }^{7}$ Most probably this selection bias decreased the strength of the associations in so far as non-responders tended to be the type of people that our study suggested were at higher risk of reporting mental distress.

The validity of some of the independent variables included in this study - for example, marital state-is probably quite high. The validity of the information about lifestyle may to a greater extent be questioned. The Spearman's rank correlation coefficients between the frequency of drinking beer, wine, and spirits according to the questionnaire and a dietary history interview conducted one to two years after a subgroup of 500 men completed the questionnaire, ${ }^{11}$ however, were found to be $0 \cdot 59-0.64(p<0.001)$ (unpublished data). The greatest validity problems are probably associated with the dependent variables. Possibly, some people with symptoms of mental distress denied them when answering the questionnaire because of concerns about anonymity. Thus the associations presented in this study are probably to some extent underestimated. Despite considerable random misclassification, however, which inevitably reduces the strength of the associations, the symptoms of mental distress we used produced a consistent pattern of distribution along several social and lifestyle variables. Furthermore, the three questions predict the occurrence of well known psychosomatic complaints of the abdomen in this population. ${ }^{12}{ }^{13}$ It should, however, be noted that we have information about only a few of many important determinants for mental health. This is reflected in the rather low $\mathrm{R}^{2}(3 \%)$ observed in the multivariate analysis (table III).

The prevalences of symptoms of mental distress of $12.5 \%$ for men and $16.8 \%$ for women are in the upper ranges compared with those in other recent studies, in which results ranged from $6 \%$ to $9 \%$ for men and $11 \%$ to $23 \%$ for women..$^{2-6}$ As other investigators used several more questions than the three we used and posed the questions within a more specific psychiatric setting, however, the possibility of comparisons is limited.

In accordance with our findings women, single people, and separated or divorced people have in most studies been found to have a higher prevalence of mental problems, even if the results for the single variables are somewhat conflicting. ${ }^{2-5}$ The strong relation between difficult financial state of the family during childhood and high prevalence of mental distress in adult life must be underlined. The harmful effects of negative emotional experiences in childhood are the core of psychodynamic theory. Possibly, difficult economy may worsen the emotional climate in the family, but the nature of this relation obviously needs further clarification. The importance of family economy in childhood is further established by the fact that the variable was also associated with irritable bowel syndrome, non-ulcer dyspepsia, and serum cholesterol concentration in this population. ${ }^{12-14}$ Thus more attention should be given to social conditions in childhood in population studies, even when focusing on different disorders.

The relation between lifestyle and mental problems has not been much investigated. We have previously reported an association between heavy coffee consumption (over eight cups a day) and mental distress in women ${ }^{15}$ and between frequent use of analgesics and mental distress in both sexes. ${ }^{16}$ The findings reported here correspond well with three other cross sectional studies, ${ }^{17-19}$ though in another community survey smoking was not significantly associated with depression..$^{20}$ Prospective data, however, are more conflicting when the causal link between lifestyle and depression is studied. ${ }^{17222}$ At present, whether some health habits play a causal part in the aetiology of depression or are consequences of the same is unclear.

This cross sectional study shows quite strong relations between the frequency of reporting symptoms of mental distress and social conditions and lifestyle, even when a simple instrument for assessing the presence of mental distress is used. The results indicate the fruitfulness of including a few questions about mental distress in different types of health survey thus providing a simple and meaningful way of connecting such symptoms with a broad variety of social and lifestyle variables.

This study was done in cooperation with the National Health Screening Service, Oslo.

\footnotetext{
1 Goldberg DP, Huxley P. Mental illness in the community. The pathway to psychiatric cure London: Tavistock Publications, 1980.

2 Henderson S, Duncan-Jones P, Byrne DG, Scott R, Adcock S. Psychiatric disorder in Canberra. A standardised study of prevalence. Acta Psychiatr Scand 1979;60:355-74.

3 Bebbington P, Hurry J, Tennant C, Sturt E, Wing JK. Epidemiology of mental disorders in Camberwell. Psychol Med 1981;11:561-79.

4 Vazquez-Barquero JL, Diez-Manrique JF, Pena C, et al. A community mental health survey in Cantabria: a general description of morbidity. Psychol Med 1987;17:227-41

5 Hodiamont P, Peer N, Syben N. Epidemiological aspects of psychiatric disorder in a Dutch health area. Psychol Med 1987;17:495-505.

6 Regier DA, Boyd JH, Burke JD, et al. One-month prevalence of menral disorders in the United States. Arch Gen Psychiatry 1988;45:977-86.
} 
7 Jacobsen BK, Thelle DS. The Tromso Heart Study: responders and non-responders to a health questionnaire, do they differ? Scand 7 Soc Med 1988;16:101-

8 Goldberg DP. The detection of psychiatric illness by questionnaire. London: Oxford University Press, 1972

9 Hansen V. Psychiatric service within primary care. Acta Psychiatr Scand 1987;76:121-8.

10 SPSS. Statistical package for the social sciences $X$. Users guide. 2nd ed. New York: McGraw-Hill, 1986

11 Jacobsen BK, Knutsen SF, Knutsen R. The Tromso Heart Study: comparison of information from a short food frequency questionnaire with a dietary history survey. Scand F Soc Med 1987;15:41-7.

12 Johnsen R, Jacobsen BK, Forde OH. Associations between symptoms of irritable colon and psychological and social conditions and lifestyle. BrMed f 1986;292:1633-5.

13 Johnsen R, Straume B, Forde OH. Peptic ulcer and non-ulcer dyspepsia-a disease and a disorder. Scand 7 Prim Health Care 1988;6:239-43.

14 Arnesen E, Forsdahl A. The Tromso Heart Study: coronary risk factors and their association with living conditions during childhood. $f$ Epidemiol Community Health 1985:39:210-4.
15 Jacobsen BK, Hansen V. Caffeine and health. BrMed f 1988;296:291.

6 Jacobsen BK, Hansen V. Mental problems and frequent use of analgesics. Lancet 1989;i:273.

17 Frederick T, Frerichs RR, Clark VA. Personal health habits and symptoms of depression at the community level. Prev Med 1988;17:173-82.

18 Kawakami N, Haratani T, Kaneko T, Koizumi A. Relationships between health practices and depressive mood among industrial workers. Fapanese Journal of Industrial Health 1987;29:55-63.

19 Parker DA, Parker ES, Harford TC, Farmer GC. Alcohol use and depression symptoms among employed men and women. Am 7 Public Health 1987;77:704-7.

20 Frerichs RR, Aneshensel CS, Clark VA, Yokopenic P. Smoking and depression: a community survey. Am F Public Health 1981;71:637-40.

21 Kaplan GA, Roberts RE, Camacho TC, Coyne JC. Psychosocial predictors of depression. Prospective evidence from the human population laboratory depression. Prospective evidence from the
studies. Am $\mathcal{F}$ Epidemiol 1987;125:206-20.

22 Aneshensel CS, Huba GJ. Depression, alcohol use, and smoking over one year: a four-wave longitudinal causal model. $\mathcal{F}$ Abnorm Psychol 1983;92:134-50.

(Accepted 4 May 1989)

\title{
Excess benign melanocytic naevi after chemotherapy for malignancy in childhood
}

\author{
Bronwyn R Hughes, W J Cunliffe, C C Bailey
}

\begin{abstract}
Objective-To see whether children who have had chemotherapy develop increased numbers of moles.

Design-Blind assessment of patients having chemotherapy and subsequent comparison with the first suitable patients matched for age and sex who were attending the clinic during the same period after having completed treatment. Controls were obtained the following year by taking the first suitable patients attending a routine dermatology outpatient clinic who matched the study groups for age and sex.
\end{abstract}

Setting-Referrals to a paediatric oncology clinic and a dermatology clinic at two city hospitals.

Patients-The group receiving chemotherapy comprised all 32 patients with acute lymphatic leukaemia, lymphoma, and rhabdomyosarcoma who were attending the paediatric oncology clinic on two mornings a week during October 1987 to March 1988. The group who had completed treatment comprised 32 patients who were attending for follow up during the same period and who matched the first group for age and sex. Thirty two other patients attending the dermatology outpatient clinic with unrelated skin conditions served as controls.

End point-Definite increase in numbers of moles on children after a course of chemotherapy.

Measurements and main results-Moles were counted by one observer on defined areas of the body and divided into those $<3 \mathrm{~mm}$ and $\geqslant 3 \mathrm{~mm}$ diameter. Patients receiving chemotherapy had a similar number of moles to the control group. By contrast patients who had completed chemotherapy had significant increases both in moles $<3 \mathrm{~mm}$ and $\geqslant 3$ $\mathrm{mm}$ and in the total number of moles. These patients were more likely to have moles on acral sites.

Conclusions-Children with substantially increased numbers of moles (benign melanocytic naevi) after successful chemotherapy for malignancy may have an increased risk of melanoma. They should be offered prolonged surveillance and cautioned about exposure to ultraviolet light.

\section{Introduction}

Patients who survive treatment that includes immunosuppression have an increased susceptiblity to cutaneous tumours and infections. ${ }^{12}$ There is no published information on the effects of benign tumours. During follow up in the paediatric oncology clinic in Leeds we noted that some children seemed to have developed an excess of moles after successful chemotherapy for leukaemia and lymphoma. As little is known about the aetiology of benign melanocytic naevi, we decided to study these children further. We aimed at assessing the cause of these moles and at learning more about the aetiology of benign melanocytic naevi.

\section{Patients and methods}

During October 1987 to March 1988 all patients attending for follow up in the paediatric oncology clinic on two mornings a week were interviewed and examined. They included patients receiving maintenance chemotherapy and those who had successfully completed chemotherapy. All patients were seen by one of us (BRH). Both dermatologists (BRH, WJC) saw the first 14 patients jointly and agreed on definition of the naevi and ensured standardisation of counts. Mole counts were performed on the children on arrival at the clinic without knowledge of the diagnosis and treatment, making that part of the study blind. The moles were counted on defined anatomical areasnamely, the face, anterior trunk, posterior trunk, upper and lower arms, upper and lower legs, palms, and soles. The moles were counted according to size and divided into those $\geqslant 3 \mathrm{~mm}$ and $<3 \mathrm{~mm}$ diameter. Only benign melanocytic naevi were included; in particular, all lesions present since birth and freckles were excluded.

The skin type was noted, as was the patient's race. Acute exposure to ultraviolet light was assessed by asking about time spent abroad-for example, on Mediterranean holidays. After the mole counts were completed disease, duration of treatment, and if applicable time since completing treatment were ascertained.

Controls were obtained from subjects attending the dermatology outpatient clinic for unrelated skin conditions. Comparisons were then made of the numbers of moles occurring among (a) normal controls, $(b)$ patients having treatment, and $(c)$ patients who had completed treatment. These patients were matched for sex, age (to within two years), and whenever possible race.

Analysis of the three groups was performed with a two way analysis of variance and the Newman-Keuls test used to determine the significance of differences 